portance, and the committee will doubtless spare no effort to ensure that it is actively continued and extended, and that in the future no risk shall be run of this fundamentally important industry passing into foreign hands. Research on chemical and other glasses has been done during the year by the laboratory, as well as by other institutions.

As is well known, one of the principal difficulties in the manufacture of optical glass lies in the choice of suitable refractory material for the pots in which it is made. The report states that the research has so far been mainly directed to the production of satisfactory pots, and that similar work on heat-resisting materials, and more generally on the behaviour of the rare earths and other substances at high temperatures, is of great importance in a large number of industrial processes. For such work a technological laboratory on a large scale is needed; and notwithstanding the economic difficulties existing, it is to be hoped that the matter will receive immediate and serious consideration.

The laboratory has earned a world-wide reputation for its successful investigation of some of the more difficult questions in aeronautics. The immediate importance of the work to the Army and the Navy has led to large additions to the equipment for aeronautical research, for which new buildings have been provided during the year; in these a second 7 -ft. and a second 4 -ft. channel have been installed. The laboratory has now five air-channels, as well as a whirling table, available for experiments on models, and with a greatly increased staff has been continuously occupied in dealing with the questions constantly arising in connection with the design o? new types of machine. In the investigation of light alloys and materials of construction a large field of work remains open, and it is satisfactory to learn that this branch of the work is receiving increased attention on an extended scale.

Provision for other new work has been rendered possible through a timely gift from Sir Charles Parsons. Arrangements have been made, at the request of the Röntgen Society, for the examination of materials employed for the protection of X-ray workers. The equipment has been installed, and the conditions of test are being determined in conjunction with the Council of the Röntgen Society.

By desire of the Ministry of Munitions, arrangements were made for the testing of prismatic compasses in considerable numbers. A paper describing the methods employed was read before the Optical Society. Assistance has been given to the Board of Trade in preparing a specification of liquid compasses for use on the lifeboats of merchant ships. The examination of the luminous dials fitted on instruments for night use constitutes an important branch of new test work, involving also the examination of the luminous radium compounds employed. Tests of radium preparations have been continued, and further improvements have been made in the methods of testing optical pyrometers, which are now being manufactured in increasing numbers in this country.

Turning to work which falls more appropriately under the heading of research, an investigation has been made into methods of magnetic testing of straight and curved bars, and improvements effected. The work has been described in a paper presented to the Institution of Electrical Engineers. A research on magnet steels is in progress. In the heat division an appreciable amount of work has been done in the investigation of the thermal conductivity of various substances, both refractory materials for furnace construction and materials employed for coldstorage work. The rate of heat transmission through roofing materials has also been investigated, and +No. 2442, VOL. 97] found to depend to a much greater degree upon- the emissivity of the surface than on the rate of conduction through the material. The loss of heat through special roofing material was thus found to be 20 per cent. greater than that through galvanised iron, owing to the difference in surface emissivity. When the special material was painted with aluminium paint, the transmission became practically identical with that of the sheet iron. Other experiments on heat loss from surfaces have been continued, and an investigation has been conducted into the qualities of British-made porcelain for pyrometer tubes.

In the Optics Division, tables for the construction of small telescope objectives from glasses of usual types have been prepared and published at the request of the Ministry of Munitions, and the results of continued experience and investigation in the design and calculation of lens systems have been communicated to the Physical Society in a series of papers. Another investigation relates to the improvement of hydrogen vacuum tubes for use in the examination of optical glasses.

The Metrology Division has been closely occupied with special test work. Some work relating to the sizes of commercial sparking plugs and tapped holes for motor engines has been carried out for the Engineering Standards Committee.

In the Engineering Department progress has been made with a number of researches. A new machine has been constructed for testing the endurance of specimens under combined bending and twisting. The methods of notched-bar impact testing have been investigated; various methods for testing the hardness and wearing properties of metals have been compared, and experiments have been carried out on the resistance of wood to reversals of stress. Shock tests on railway couplings have been made. The measurement of the rate of growth of cracks in the Tower of London is a matter of general public interest. In Aeronautics the investigation of stability has been extended to the case of curvilinear motion.

In the Metallurgy Department, investigatory work has been mainly confined to matters of immediate importance; some interesting papers relating to appliances for metallurgical research have been read before the Institute of Metals. Valuable papers have been contributed to various institutions by members of the staff of the Froude Tank, which has, however, also been occupied almost entirely with urgent work for the Admiralty.

The report makes it clear that the laboratory has borne its full share of the burden which has fallen upon the nation, and the country is indebted to the director and his staff for their strenuous efforts in the furtherance of technical efficiency.

\section{THE RECENT DEVELOPMENT OF GF.RMAN AGRICULTURE}

THE fact that on each hundred acres of cultivated land Germany feeds seventy of her people while Britain can only support forty-five has rightly received wide publicity in the daily Press. The memorandum by Mr. T. H. Middleton, Assistant-Secretary, Board of Agriculture and Fisheries, which explains how Germany does this, should be studied by all who have the welfare of British agriculture at heart. The two chief factors in the recent remarkable development of German agriculture are her settled economic policy and her well-thought-out system of agricultural education. It was the belief that he was essential to the community, and that his land would not be allowed to go out of cultivation, rather than the extra profit 
on his wheat, that has inspired the German farmer to greater efforts during the last ten years. The need for well-educated men as managers of estates is more commonly recognised in Germany than in England; hence a career is open to successful students frcm the training institutions of Prussia, while the English student who lacks the capital to farm on his own account must look abroad for an outlet for his knowledge of practical agriculture.

Mr. Middleton believes that our system of education, though starting thirty years behind that of Germany, mainly wants time to grow. It is unfortunate that it had only just started before the war and that results will be sought at a time when patience will be necessary but very difficult to exercise. The chief immediate cause of the increased productivity of German soil is the increase in the use of artificial manures. The German farmer is no more skilful than the British, but his natural obedience to authority leads him to apply artificial manures in such quantities as his instructors, relying on the systematic work of the experiment stations, may from time to time direct. Twice as much nitrogen, one-third more phosphate, and five times as much potash are used in Germany as on an equal area of our cultivated land. As regards the two former manures, we import nearly three tons more feeding stuffs per one hundred acres than the Germans, and this should balance to some extent the smaller amounts of nitrogen and phosphate applied direct to the soil; but careless storage of farmyard manure results in the loss of some 50 per cent. of the nitrogen and a good deal of the phosphate, so that far less than the theoretical amount ever gets to the growing crop. Germany is fortunate in that she has not only immense deposits of potash salts, but also vast areas of light soils able to give abundant returns from these manures when skilfully applied. This combination plays an important part in the recent progress of German farming.

\section{THE ROYAL AIRCRAFT FACTORY INQUIRY.} $\mathrm{HE}$ whole question of the Royal Aircraft Factory
administration and cost seems to turn on whether it is to be regarded as an experimental or a productive concern. If it is to be regarded as a factory for the production of service machines, then there is little doubt that it is not administered as efficiently as it might be. But if it is to be regarded as a purely, or at least chiefly, experimental establishment, then the case is completely altered. In the development of a new industry, such as aeronautics, there must be a certain amount of experiment, and in modern times the tendency is to arrive at a satisfactory result by the application of science to the fullest possible extent, rather than to attain that result by a lengthy process of trial and error. The inevitable result of the scientific method is that it appears as though a considerable amount of money is being wasted with no appreciable result, but in reality the money is being well spent if it leads to scientific results of a widely useful nature. The Royal Aircraft Factory should therefore be judged by its achievements in the advance of aeronautical science rather than by its actual output of machines for service use. There can be no doubt at all that the work done at the factory, in conjunction with the model experiments and mathematical investigations at the National Physical Laboratory, has elucidated many questions of vast importance concerning the design and stability of aeroplanes in a way which would perhaps never have been done by private firms, where output is the primary consideration. Once it is admitted that this scientific information NO. 2442 , VOL. 97$]$ is needed, the Royal Aircraft . Factory stands justified by its past work. By all means reorganise, if by such reorganisation increased efficiency can be obtained, but let it not be at the expense of the exceedingly valuable experimental work which is being done, and which can be done in no other way at the present time.

It is often argued that private firms can produce machines equal to those of the Factory, without spending so much time and money on the experimental side. This is by no means true, since the results of such experimental work at the Factory and elsewhere have always been available to a large extent to any who cared to avail themselves of them, and many good points in proprietary machines are indirectly due to this fact. There is still an inclination on the part of some firms to view the scientific side of the subject with suspicion, and even to depreciate experimental aeronautics altogether, but surely the sooner experimental results become more widely known the better it will be for the future development of the aeronautical industry. In the provision of these scientific fundamentals of aeronautics the Royal Aircraft Factory has played, and is playing, an important part, and any attempt at reorganisation which would impair its utility as an experimental establishment, and reduce it to the level of a productive factory for existing designs, would be a great mistake at the present early stage of aeronautical development.

\section{LORD KELVIN AND TERRESTRIAL MAGNETISM. ${ }^{1}$}

I IKE most branches of physics, terrestrial mag1 netism has associations with the name of Kelvin, and, characteristically enough, these associations are at the two confines of the subject, the immediately practical, and the speculative. Lord Kelvin, I need scarcely remind you, introduced important changes of design into compasses, and the construction of compasses was an important object of the Glasgow firm which eventually bore his name.

The other point of contact between Lord Kelvin and terrestrial magnetism, as already mentioned, relates to theory. All here know that there occur from time to time phenomena known as magnetic storms, during which there are difficulties in carrying on ordinary telegraphy. There has long been a belief that the sun is the principal, if not the only, source of magnetic storms, and of the less striking regular changes every day visible. Lord Kelvin directed attention to the difficulties in the way of accepting any sensible direct magnetic action between the sun and the earth. His earliest remarks on the subject, to which I shall refer, are contained in a short note on p. 'I54 of vol. iv. of his "Mathematical and Physical Papers." "The sun's magnetisation," he said, "would ... need to be 120 times as intense as the earth's to produce a disturbance of $\mathrm{I}^{\prime}$ in declination even by a complete reversal in the most favourable circumstances."

The much later communication, to which I next refer, was made in 1892 to the Royal Society, on an occasion-a presidential address-when original contributions to science are unusual. Lord Kelvin, however, devoted fully half his address to terrestrial magnetism. After referring to various solar and terrestrial magnetic phenomena he adds (loc. cit., p. 307) :--" But now let us consider ... the work which must be done at the sun to produce a terrestrial magnetic storm." He then quotes from a paper by the late Prof. W. G. Adams data relating to a magnetic storm of June 25,1885 , and proceeds :- "To produce such changes as these by any possible dynamical action

1 Abridged from the Seventh Kelvin Lecture delivered before the Institu tion of Electrical Engineers on February 17 , by Dr. C. Chree, F.R.S. 